\title{
7T MRI Fractionated Dipole Antenna for Carotid Imaging
}

\author{
Mortensen, Nicolai; Hinge, Lars; Zhurbenko, Vitaliy; Boer, Vincent $O$.
}

\section{Published in:}

Proceedings of 2020 European Microwave Conference

Link to article, DOI:

10.23919/EuMC48046.2021.9337985

Publication date:

2021

Document Version

Peer reviewed version

Link back to DTU Orbit

Citation (APA):

Mortensen, N., Hinge, L., Zhurbenko, V., \& Boer, V. O. (2021). 7T MRI Fractionated Dipole Antenna for Carotid Imaging. In Proceedings of 2020 European Microwave Conference (pp. 1063-1066). IEEE.

https://doi.org/10.23919/EuMC48046.2021.9337985

\section{General rights}

Copyright and moral rights for the publications made accessible in the public portal are retained by the authors and/or other copyright owners and it is a condition of accessing publications that users recognise and abide by the legal requirements associated with these rights.

- Users may download and print one copy of any publication from the public portal for the purpose of private study or research.

- You may not further distribute the material or use it for any profit-making activity or commercial gain

- You may freely distribute the URL identifying the publication in the public portal 


\title{
7T MRI Fractionated Dipole Antenna for Carotid Imaging
}

\author{
Nicolai Mortensen ${ }^{\# 1}$, Lars Hinge ${ }^{\# 2}$, Vitaliy Zhurbenko ${ }^{\# 3}$ Vincent O. Boer ${ }^{* 4}$ \\ \#Electromagnetic Systems, Department of Electrical Engineering, \\ DTU Elektro, Technical University of Denmark, Kgs. Lyngby, Denmark \\ *Danish Research Centre for Magnetic Resonance, Centre for Functional and Diagnostic Imaging and Research, \\ Copenhagen University Hospital Hvidovre, Hvidovre, Denmark \\ $\left\{\mathrm{s} 154332^{1},{ }^{2}\right.$ s154349\}@student.dtu.dk, ${ }^{3}$ vz@elektro.dtu.dk ${ }^{4}$ vincentob@drcmr.dk
}

\begin{abstract}
T MRI is a promising candidates for detecting carotid plaques prematurely. Specialized antenna are required for imaging of different body parts, along with coilformers to hold the antenna close to the desired body area. A fractionated dipole antenna is simulated and fabricated in order to test the performance of the antenna, and coilformer, in imaging the carotid region. 7T MRI test showed a $86 \%$ magnetic field strength reduction in a makeshift phantom, at approximate carotids depth, compared to the magnetic field at the skin of the phantom.
\end{abstract}

Keywords - 7T MRI, Magnetic Resonance, Coilformer, Carotid, Fractionated dipole

\section{INTRODUCTION}

The main challenge in 7T MRI applications is the electrical field produced by the antenna. 7 tesla MRI operate at microwave frequency $(298 \mathrm{MHz})$, so antennas can induce high amounts of power into the patient, generating excessive heat in the body. For this purpose a fractionated dipole antenna, similar to the one proposed in [1], is used to reduce the electrical field. The fractions in the dipole antenna yields, with the chosen antenna length, a more uniform current distribution reducing the electric field radiated by the antenna. Placement of the antenna is desired to be as close as possible to the body part subjected to imaging, namely the carotid artery. For this purpose a coilformer design from [2] is produced to place the antennas around the neck.

\section{Methods}

To compare antenna efficiency, a parameter is introduced given by $\frac{B 1_{+}}{\sqrt{S A R}} . B 1_{+}$or $B 1_{-}[\mathrm{T}]$ is a measure of the rotation of the magnetic field, which is desired to be as high as possible in MRI antennae. The specific absorption ratio (SAR) $\left[\frac{\mathrm{W}}{\mathrm{kg}}\right]$ measures the energy deposited in the dielectric (body). When investigating the efficiency of the antennae, the maximum SAR result in the phantom will always be used. Naturally this parameter is desired to be as high as possible, so the power to the antennae can be increased as much as possible without excessive heat generation in the patient. The SAR measurements are averaged over $10 \mathrm{~g}$ for all future purposes. The goal is to create a simulation of the antennae and compare the results to real 7T MRI imaging to determine the viability of the antenna and coilformer for carotid imaging.

\section{DESIGNING THE DIPOLE AND BUILDING EM (CST) MODEL}

To evaluate the dipole a CST model is created. The dipole is placed $1 \mathrm{~cm}$ above a dielectric, with electrical characteristics resembling human skin. The antenna is placed along the z-axis, and the dielectric (body) along the y-axis. Dimensions used in the simulation can be found in the Table 1 .

Variable capacitors and inductors are used to vary the impedance in the connections of the fractionated dipole, resulting in multiple simulations. From the simulation the B1-fields and SAR can be exported to evaluate the antenna. The fractionated dipole antenna with different connecting lumped elements is compared similarly to [1], the results can be seen in Fig. 1. Additionally a combined loop-dipole [3] antenna is simulated, where a fractionated dipole is placed on top of a loop coil, this simulation result is also shown in Fig 1.

From plot (4) the SAR can be seen to be very low for the 100 and $132 \mathrm{nH}$ fractionated dipole, the $B 1_{+}$is also lower seen in plot (2) and (3), however not enough for these antenna to be superior to the other candidates as seen in plot (6). Choosing and impedance of $160 \Omega$ ie. an inductor of $85 \mathrm{nH}$, the antenna are now placed around the coilformer model [2], the setup and placement of the dielectric (neck) can be seen in Fig. 2.

Table 1. CST fractionated dipole dimensions

\begin{tabular}{llllll}
\hline $\begin{array}{l}\text { Conductor } \\
\text { width } \\
(\mathrm{mm})\end{array}$ & $\begin{array}{l}\text { Width } \\
(\mathrm{mm})\end{array}$ & $\begin{array}{l}\text { Length } \\
(\mathrm{mm})\end{array}$ & $\begin{array}{l}\text { Thickness } \\
(\mu \mathrm{m})\end{array}$ & $\begin{array}{l}\text { Fraction } \\
\text { spacing } \\
(\mathrm{mm})\end{array}$ & $\begin{array}{l}\text { Source } \\
\text { spacing } \\
(\mathrm{mm})\end{array}$ \\
\hline 10 & 10 & 30 & 35 & 2 & 10 \\
\hline
\end{tabular}



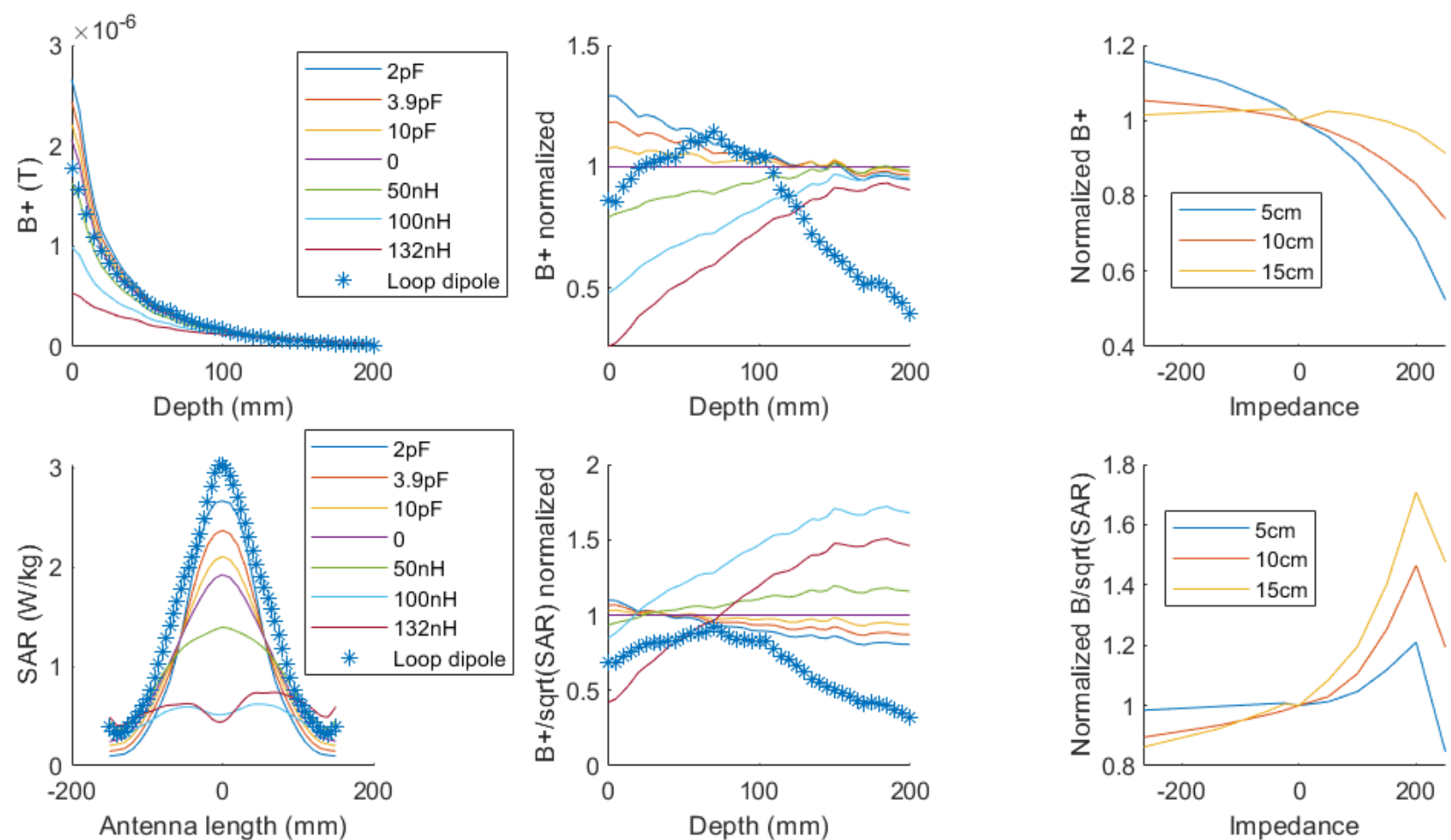

Fig. 1. From top left and in reading direction: (1) B+ as a function of dielectric depth "y-axis" at dipole center. (2) B+ as a function of dielectric depth at dipole center relative to non-fractionated dipole. (3) For 3 different depth, normalized B+ on the y-axis, and imaginary impedance of lumped element connecting the dipole on the x-axis. (4) SAR as a function of antenna lengths, at the dielectric surface directly above antenna. (5) Normalized $\frac{B+}{\sqrt{S A R}}$ as a function of depth. (6) For different depths, normalized $\frac{B+}{\sqrt{S A R}}$ as a function of imaginary impedance.

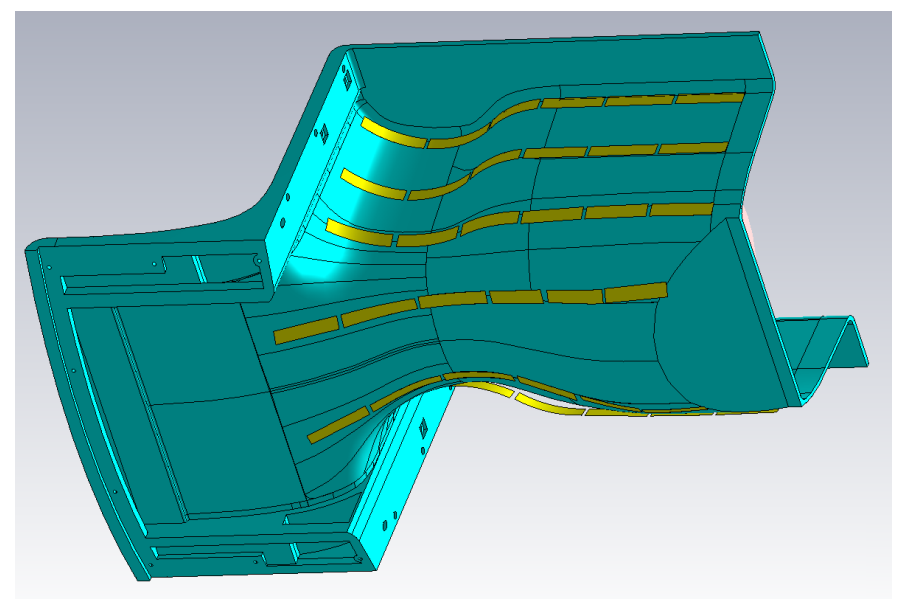

(a)

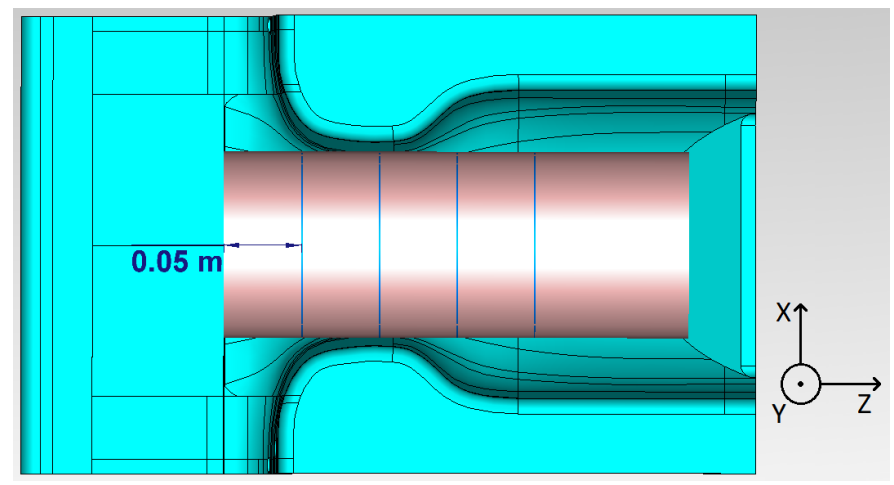

(b)

Fig. 2. (a) Fractionated dipole placement on coilformer in CST simulation. (b) Dielectric placement in coilformer used for CST simulation
To evaluate the performance of the antennae configuration, a surface plot along the blue lines seen in Figure 2 is created. The result can be seen in Fig. 3

The SAR levels are highest in the middle of the cylinder while the $B 1_{+}$is concentrated on the sides of the cylinder. Looking at the $\frac{B 1_{+}}{\sqrt{S A R}}$ plot, the ratio should preferably be higher at the lower surface plots at $\mathrm{z}=50 \mathrm{~mm}$ and $\mathrm{z}=100 \mathrm{~mm}$ to focus on the carotid artery. This would however require the antennas to be moved further to back along the z-axis, which is restricted by the coilformer. Imaging at the throat of the neck would also require a different coilformer setup for optimal antennae placement.

\section{FABRICATION OF COILFORMER}

To test the antenna, the coilformer model used in the CST simulations [2] has to be fabricated. 22 separate pieces was 3D printed and glued together to form the coilfomer. Extra "feet" and supports for the coilformer was later printed to add overall stability. The coilformer enables the antennae to be placed comfortably around the required imaging but can also restrict antennae placement if not formed correctly. The final tests is also to test if the coilformer can provide adequate antenna placement for carotid imaging Coilformer dimensions are shown in Table 2.

The finalised printed coilformer is shown in Fig. 4 


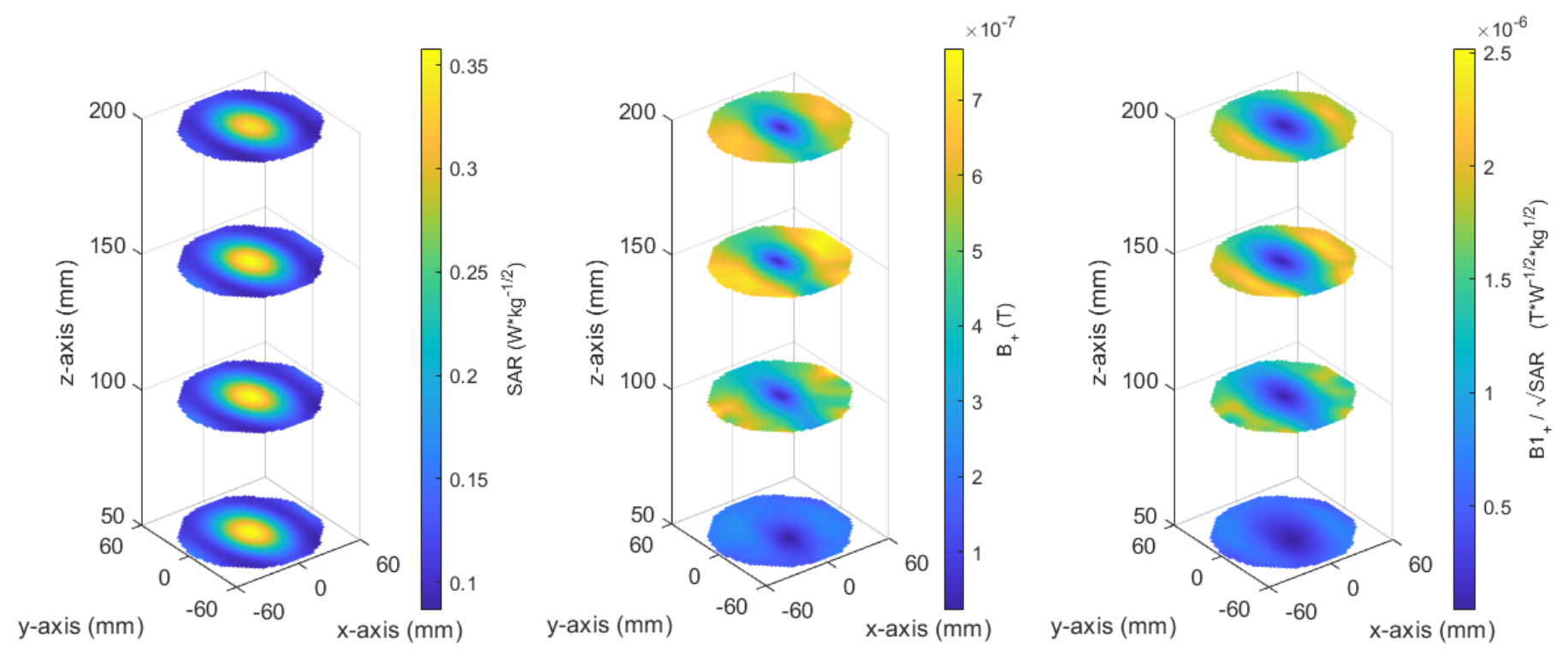

Fig. 3. Surface plots of SAR, B1+ and $\frac{B 1_{+}}{\sqrt{S A R}}$ for the neck cylinder at z-coordinates defined in Fig. 2

Table 2. Coilformer dimensions

\begin{tabular}{l|ll}
\hline Parameter & Value & Unit \\
\hline Width (x) & 194 & $\mathrm{~mm}$ \\
Height (y) & 227 & $\mathrm{~mm}$ \\
Depth (z) & 474 & $\mathrm{~mm}$ \\
Max. tested load & 5 & $\mathrm{~kg}$ \\
\hline
\end{tabular}

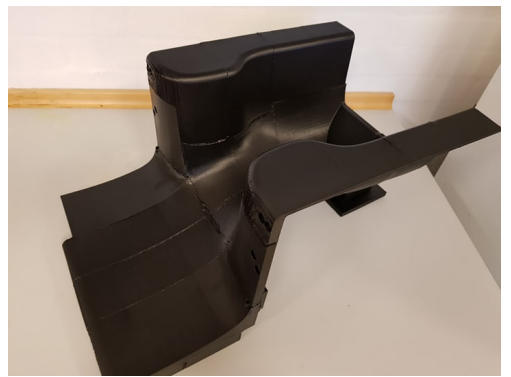

Fig. 4. 3D printed coilformer used for testing at the $7 \mathrm{~T}$ MRI

\section{ANTENNA FABRICATION}

The antenna design is created in Keysight ADS and printed on RT/duroid 6002PTFE Ceramic 6in x 6in plate. The material has a low loss tangent, and is still flexible enough to bend around the shape of the coilformer. The ADS model created is also used to simulate the voltage across the matching components, to ensure the voltage does not exceed the voltage rating of the matching capacitors. Simulation showed that a maximum voltage across matching capacitors reached $860 \mathrm{~V}$ when supplied with $8 \mathrm{~kW}$, which is the maximum power for the 7T MRI used for testing. The voltage rating of the capacitors is $1500 \mathrm{~V}$ so well above the simulated voltage. In Fig. 5 the design used for antenna print and simulation can be seen along with the 2 finalized antennae placed on the coilformer. A copper backplate is added on the fabricated antenna to reduce the electric field generated by the matching components, this is the yellow plate also seen in Fig. 5 (a). The matching is done with a phantom consisting of a 5 liter water bag inside the coilformer, the top antenna was nearly matched and no components was added. The bottom antenna is matched with 2 capacitors in series. All capacitors and BNC connectors are, of course, non-magnetic.

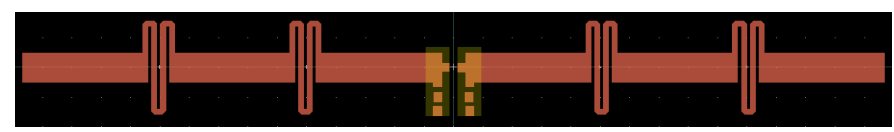

(a)

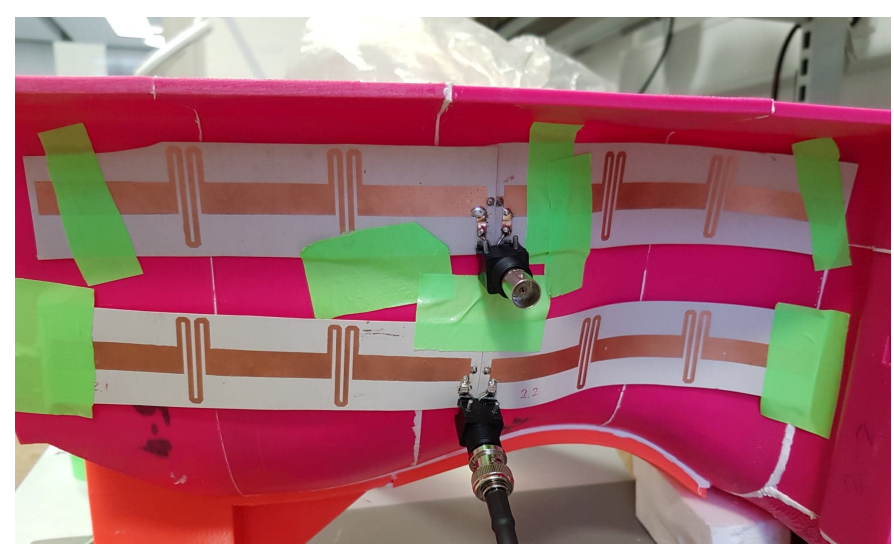

(b)

Fig. 5. (a) Keysight ADS model of the fabricated dipole antenna. (b) Fabricated dipole antennae placed on the coilformer

The isolation is measured by placing the antennae on a plat surface an varying the distance between the middle of the conductor, the result in shown in Table 3.

\section{RESULTS FROM TESTING}

The antenna and coilformer setup was tested at the 7T MRI scanner, and a coronal $B 1_{+}$map through the neck phantom 
Table 3. Antenna isolation

\begin{tabular}{l|llll}
\hline Seperation distance $(\mathrm{cm})$ & 3.5 & 4 & 5 & 6 \\
\hline Isolation $(\mathrm{dB})$ & 10.6 & 12.2 & 14.5 & 18.1 \\
\hline
\end{tabular}

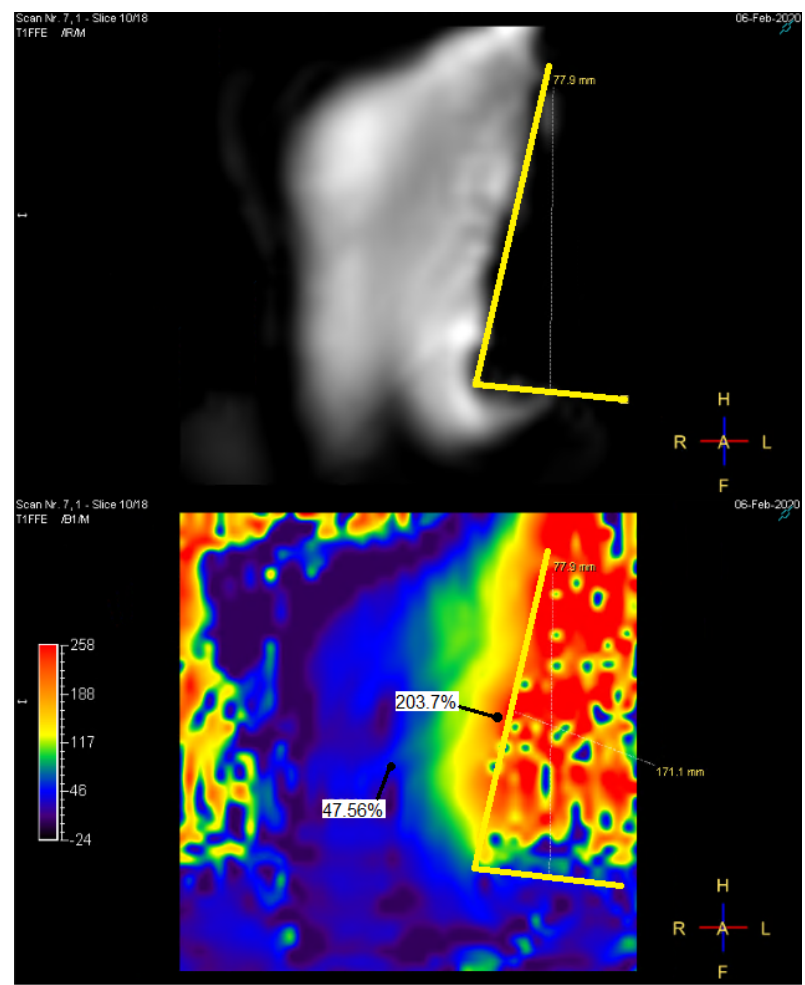

Fig. 6. On top the imaging results shows the magnitude of the B-field through the neck phantom, and below the coronal $B 1_{+}$map through the neck phantom. The yellow line represents the outline of the coilformer. Two points are added to the image displaying relative field strengths

was created, the result in shown in Fig. 6.

From the imaging results, the antenna can be seen to generate a consistent magnetic field along the antenna direction (yellow line) as expected. The field strengths in the two point created on the image reduces from a relative of $203.7 \%$ to $47.56 \%$ a few centimeters in. The magnetic field reduces quickly inside the phantom and the $B 1_{+}$at depth might not be sufficient for good SNR. The CST simulations also shows a large drop in the magnetic field strength at depth. However if the electric-field is low, the power can be turned up without causing damage to the patient, and a sufficient magnetic field and a good SNR at carotid depth can still be acquired.

\section{VIICONCLUSION}

A fractionated dipole design is verified through EM simulation to give lower electric field, and thereby increased $\frac{B 1_{+}}{\sqrt{S A R}}$ ratio, as opposed to the non-fractionated counterpart. An optimal impedance connecting the fractionated dipole has been verified through EM simulation. The dipole has been fabricated, impedance matched, and tested on a 7T MRI scanner. A 3D Printed coilformer is produced with the goal of holding the antennas close to the carotid artery to provide quality images. Final results show a broad magnetic field but with a somewhat low magnetic field at the approximate depth of the carotid artery. CST simulations verify a large drop in magnetic field at depth. Simulations show a large drop off in magnetic field strength at the base of the neck, suggesting a different setup for imaging this area. Simulation also show a weak magnetic field at the throat and back of the neck. Imaging the back of the neck can easily be fixed by adding more antenna, but acquiring an adequate magnetic field at the throat would require a different coilformer setup, with antennae support at the throat. Future work is aimed at constructing an 8-channel dipole array for optimal transmit receive characteristics in the neck region, to provide better quality imaging of the carotid artery

\section{REFERENCES}

[1] A. Raaijmakers et al., "The fractionated dipole antenna: A new antenna for body imaging at 7 Tesla : The fractionated dipole antennas," Magnetic Resonance in Medicine, vol. 75, pp. 1366-1374, 2016.

[2] J. Cohen-Adad et al., "32-channel RF coil optimized for brain and cervical spinal cord at $3 \mathrm{~T}: 32 \mathrm{ch}$ head/c-spine coil at $3 \mathrm{~T}$," Magnetic Resonance in Medicine, vol. 66, p. spcone, 2011.

[3] M. A. Ertürk et al., "A 16-channel combined loop-dipole transceiver array for 7 tesla body mri," Magnetic Resonance in Medicine, vol. 77, pp. 884-894, 2017. 